\title{
Study on the Construction of Innovation Driven Development Evaluation Index Method System
}

\author{
Xiaobing $\mathrm{Pei}^{1, \mathrm{a}}$, Huifen $\mathrm{Chen}^{2, \mathrm{~b}}$ \\ ${ }^{1}$ School of management, Tianjin University of Technology, Tianjin 300384, China; \\ ${ }^{1}$ School of management, Tianjin University of Technology, Tianjin 300384, China; \\ a1130125687@qq.com, bchenhuifen0000@foxmail.com
} Keywords:innovation, innovation driven development,dynamic multidimensional evaluation index
method system

\begin{abstract}
Based on the summary of innovation driven development connotation, this paper points out the essence of the innovation driven the development, trend of the strategic development features and the four combinations of innovation driven development, according to the area and the content of the evaluation , classify evaluation system, focus the process of innovation chain ,that is, the driving force of innovation, development modes and innovation output and dynamic multidimensional evaluation index system is proposed to construct a dynamic multidimensional evaluation index method system.
\end{abstract}

\section{Introduction}

China is facing increased human costs, structural imbalance, foreign investment slowdown, environmental and resource constraints, relying on land, resources, capital, labor and other traditional elements of investment is difficult to sustain the development of economy.At present, the traditional power of economic growth has weakened, we must strengthen the structural reform and accelerate the implementation of innovation driven development strategy.

\section{2. literature Review}

\subsection{Problem Formulation.}

Since the creation of Pete's Innovation Theory[1], scholars and governments pay close attention to innovation and actively promote to carry out innovative areas using different evaluation system , according to the evaluation content, evaluation method, evaluation object and evaluation scope to classify.From the scope of the evaluation can be divided into national, regional (municipality), parks and universities, respectively, examples: Insead2013 global innovation index, regional science and technology innovation performance evaluation index system; national level according to the evaluation content is divided into the type of policy, technology and knowledge, innovation ability and competitiveness of the evaluation index, respectively examples: ITIF \& Kauffman OECD index of innovation policy, science, technology and industry scale, Asia Pacific Economic Cooperation (APEC) state of knowledge economic index (KSI), European Innovation Scoreboard (EIS and WEF), the global competitiveness index (GCI) 2013-2014.we can see that the competitiveness evaluation index for innovation ability is very rich, but specific for Chinese evaluation index system is very few,the driver development evaluation index system innovation, it is not simply a innovation driven performance evaluation system, but lay the theoretical foundation from the macro deployment to the micro implementation level.

\subsection{Review on the index evaluation system.}

The connotation of innovation driven development is summarized as follows.In the book of "National Competitive Advantage", Potter first proposed a "Diamond Theory", which is composed of 4 kinds of elements "Diamond System" to describe the composition of competitive environment, to reveal the factors that affect the growth of productivity and yield in a certain area ". Then, he points out that the economic development of a country or region will experience 4 stages of production 
factor, investment driven, innovation driven and wealth driven. There no competitiveness...... The competition in various industries and sectors begins to deepen and expand...... New industries with competitive industries are also produced by the related industries...... In addition to improving foreign technology and production methods, but also the performance of their own creativity...... Enterprises can continue to innovate; their innovation ability and the formation of other new industries, the original power". This is the essence of "innovation driven".Xi Chen,2013[4] thinks innovation driven development is to rely on innovation, so that the production elements of a high degree of integration, agglomeration, and sustainable to create wealth, thereby driving economic healthy steady development.L.W.Zhang,2013[3] thinks the purpose of innovation is to the essence of development.L.J.Wang,2014[2] thinks the innovation driven development is through the combination of factors and the interaction of the system, through the dynamic and complex economic process to realize the endogenous growth, and thus optimize allocation of resources, provide the overall development strategy for the sustainable development of economy.

Innovation driven development is the economic development, so many researchers pay attention to innovation input and innovation output, the majority of researchers generally draw on innovation oriented country/city evaluation index system including innovation level, innovation ability[5], lack of comprehensive characterization of innovation driven source and the evaluation of dynamic process development mode including innovation environment, innovation culture and ecology, resources, environment.The dynamic multidimensional evaluation index system (DMEMIS) is a new process of innovation driven development, which reflects the driving force of economic development, the development model and the impact on environment, resources and ecology.

\section{Evaluation method system framework}

Propose a new model of the innovation system based on the model of rietsch, which is a comprehensive evaluation method,combined with EIS,China Innovation Index 2013, Insead global competitiveness report, Shanghai innovation driven and development evaluation index system etc.

Evaluation method system is divided into three aspects, namely, the innovation output, the driving force, the development model. From the aspects of intellectual property rights and technology application, the innovation output is evaluated, and the intangible output of innovation is added in order to increase the soft index of evaluation. The driving force is concerned with the interaction between the elements of innovation, from the innovation of the infrastructure, technological innovation, talent investment, innovation policy support and comprehensive evaluation. The development mode of the industrial structure upgrade and sustainable, coordination.

Tab1. Innovation driven development evaluation system -dynamic multidimensional evaluation method of index system

\begin{tabular}{|c|c|c|}
\hline First index & Second index & Third index \\
\hline \multirow{8}{*}{$\begin{array}{c}\text { Innovative } \\
\text { output }\end{array}$} & \multirow{4}{*}{ intellectual property } & SCI average citation \\
\hline & & R\&D personnel per 10000 patent index \\
\hline & & every 100 enterprises trademark ownership index \\
\hline & & $\begin{array}{l}\text { the number of invention patents accounted for the proportion of patent } \\
\text { authorization number }\end{array}$ \\
\hline & \multirow{4}{*}{ technology application } & $\begin{array}{l}\text { technology market turnover index of millions of scientific and } \\
\text { technological activities }\end{array}$ \\
\hline & & the new product value-added \\
\hline & & $\begin{array}{l}\text { new product sales revenue accounted for the proportion of main } \\
\text { business income }\end{array}$ \\
\hline & & high-tech product exports or total exports \\
\hline
\end{tabular}




\begin{tabular}{|c|c|c|}
\hline & \multirow{3}{*}{ intangible output } & intangible property \\
\hline & & innovative products and services \\
\hline & & online creation \\
\hline \multirow{14}{*}{ Driving force } & \multirow{4}{*}{ Infrastructure } & number of institutions of higher colleges \\
\hline & & number of scientific research institutions \\
\hline & & the proportion of enterprises and institutions with R \& D \\
\hline & & the number of books per million people (volume / million) \\
\hline & \multirow[b]{2}{*}{ Technological innovation } & the per capital contribution of high tech industry \\
\hline & & $\begin{array}{l}\text { High tech product output value accounted for the proportion of total } \\
\text { industrial output value }\end{array}$ \\
\hline & \multirow{4}{*}{$\begin{array}{l}\text { Innovation Talent } \\
\text { Investment }\end{array}$} & the average years of education \\
\hline & & the population of a lifetime study \\
\hline & & R\&;D personnel accounted for the proportion of employed population \\
\hline & & technical staff accounted for the proportion of total employees \\
\hline & \multirow[t]{2}{*}{ Innovation policy support } & $\begin{array}{l}\text { scientific and technological appropriation account for financial } \\
\text { appropriation }\end{array}$ \\
\hline & & the proportion of the enterprise number enjoyed the tax deduction \\
\hline & \multirow{2}{*}{ other } & information index \\
\hline & & GDP index per capital \\
\hline \multirow{10}{*}{$\begin{array}{c}\text { Development } \\
\text { mode }\end{array}$} & \multirow{2}{*}{$\begin{array}{l}\text { upgrading of an industrial } \\
\text { structure }\end{array}$} & coordination of the development of the three industries \\
\hline & & The second,third industrial production efficiency coordination degree \\
\hline & \multirow{8}{*}{ sustainable development } & $\begin{array}{l}\text { the value-added of information service industry accounted for regional } \\
\text { GDP }\end{array}$ \\
\hline & & the value-added of the financial accounted for the national financial \\
\hline & & The value-added of culture industry accounted for regional GDP \\
\hline & & $\begin{array}{l}\text { Energy consumption standard coal for production value per } 10000 \\
\text { yuan }\end{array}$ \\
\hline & & environmental quality index \\
\hline & & comprehensive utilization of industrial solid waste \\
\hline & & centralized treatment rate of urban sewage \\
\hline & & Proportion of days with air quality reached the second level \\
\hline
\end{tabular}

\section{The principle of the index selection and data processing method}

Combine the horizontal and longitudinal depth width of index; index selection can be combined with the operation and practicability, select the clear meaning and available of index data ; the representative and systematic index, which can reflect the profound connotation of the innovation driven development, rather than a comprehensive spread. Then select the indicators, focusing on the system, can reflect the inherent mechanism of innovation driven development.

First of all, concept of identification, which is the basis for excluding the meaning of cross index. The second step is to analyze the exact meaning of each index and eliminate redundancy index . The third step, choose data processing methods . including(1) the statistics of the original data;(2) the use of Z-score standard method to use SPSS software.The fourth step,determine the weight of the index 
and calculation. The fifth step, analysis the various indicators and the overall results of the innovation driven development evaluation method system. The sixth step, continuous modification and correction, to ensure that the guidance of practice.

\section{Summary}

The evaluation method system of innovation driven development is limited to the theoretical exploration and the construction of the method system.Innovation driven development requires further deployment of the implementation ,the economic transformation and upgrading of different regions of the development model or case is an interesting direction of the practitioners and researchers.

\section{References}

[1]. Michael Porter. National competitive advantage [M]. Beijing: China Press, 2002, P122-127.

[2]. Wang Laijun. Based on innovation driven research on industrial cluster upgrading [D]. Doctoral dissertation, the CPC Central Party school, China 2014,P35-39

[3]. Zhang Laiwu. On the development of innovation driven development [J]. China soft science, $2013(1): 1-5$.

[4]. Chen Xi. The path of innovation driven development strategy choice [J]. economic issues, 2013 (3):42-46

[5]. Wu you et al. Construct an development evaluation index system of innovation driven [J], 2014 (8): 88-92. 